\title{
FAAH polymorphism (rs324420) modulates extinction recall in healthy humans: an fMRI study
}

\author{
Jennifer Spohrs ${ }^{1} \cdot$ Martin Ulrich $^{2} \cdot$ Georg Grön ${ }^{2} \cdot$ Paul L. Plener $^{1,3} \cdot$ Birgit Abler $^{2}$ (i)
}

Received: 29 July 2021 / Accepted: 24 November 2021 / Published online: 10 December 2021

(c) The Author(s) 2021

\begin{abstract}
Gold standard treatments for anxiety- and trauma-related disorders focus on exposure therapy promoting extinction learning and extinction retention. However, its efficacy is limited. Preclinical and particularly animal research has been able to demonstrate that homozygosity for the fatty acid amide hydrolase $(F A A H) \mathrm{C} 385 \mathrm{~A}$ allele, similar to FAAH inhibition, is associated with elevated concentrations of anandamide (AEA) and facilitates extinction learning and extinction recall. However, in humans, the underlying neurobiological processes are less well understood, and further knowledge might enhance the development of more effective therapies. In this functional magnetic resonance imaging (fMRI) study, a fear conditioning, fear extinction and extinction recall paradigm was conducted with 55 healthy male adults. They were genotyped for the $F A A H$ single-nucleotide polymorphism (SNP) rs324420 to investigate differences related to extinction recall in neural activation and State-Trait Anxiety Inventory (STAI) ratings between AC heterozygotes and CC homozygotes (FAAH C385A SNP). Differential brain activation upon an unextinguished relative to an extinguished stimulus, was greater in AC heterozygotes as compared to $\mathrm{CC}$ homozygotes in core neural structures previously related to extinction recall, such as the medial superior frontal gyrus, the dorsal anterior cingulate and the anterior and middle insular cortex. Furthermore, AC heterozygotes displayed higher AEA levels and lower STAI-state ratings. Our data can be interpreted in line with previous suggestions of more successful extinction recall in A-allele carriers with elevated AEA levels. Data corroborate the hypothesis that the endocannabinoid system, particularly AEA, plays a modulatory role in the extinction of aversive memory.
\end{abstract}

Keywords Endocannabinoid system $\cdot$ Anandamide $\cdot$ Anxiety disorders $\cdot$ FAAH rs324420 $\cdot$ Extinction recall

\section{Introduction}

The past decades have seen major advances in the understanding and treatment of stress and anxiety disorders, such as posttraumatic stress disorder (PTSD), panic disorder or phobias, which are highly frequent and debilitating psychiatric disorders [1]. Current treatment options, such

Parts of the results have been included in the doctoral thesis of the first author (Jennifer Spohrs).

Birgit Abler

birgit.abler@uni-ulm.de

1 Department of Child and Adolescent Psychiatry/ Psychotherapy, Ulm University, Ulm, Germany

2 Clinic for Psychiatry and Psychotherapy III, Ulm University, Ulm, Germany

3 Department of Child and Adolescent Psychiatry, Medical University Vienna, Vienna, Austria as psychopharmacological treatments and exposure-based psychotherapy, have been demonstrated to be effective; however, they leave room for improvement [2]. To further advance available treatment options, neuromodulatory, genetic, physiological and behavioral processes involved in stress- and anxiety disorders have been intensely studied and have expanded knowledge regarding underlying processes. Among others, particularly, the endocannabinoid system (ECS) has become a subject of interest [3, 4] as previous research suggests a modulating role in stress- and anxiety disorders, especially in balancing the homeostasis after stress. Accordingly, altered endocannabinoid levels were identified in stress-related disorders, such as PTSD [5].

The plant Cannabis sativa has been consumed for its anxiolytic effects for thousands of years. Recently, major research advances were achieved regarding the endocannabinoid system, with its well-known pharmacological accessibility [6]. Research supports that particularly modulation of anandamide (AEA) transmission, one of the main 
endocannabinoids, could have beneficial effects in the treatment of anxiety. Accumulating evidence indicates that the genetic single-nucleotide polymorphism (SNP) rs324420 (C385A) in the fatty acid amide hydrolase $(F A A H)$ gene, coding for the AEA degrading enzyme, modulates processes associated with extinction learning [7, 8]. Extinction learning is essential for effective exposure therapies in clinical settings and its efficacy can be tested by extinction recall checks [9]. Approximately $38 \%$ of the European population are carriers of the A-allele (33\% AC heterozygotes, 5\% AA homozygotes) for the rs $324420 \mathrm{SNP}$, leading to the FAAH enzyme being more vulnerable to proteolytic degradation. Consequently, in AA homozygotes the expression of FAAH activity is assumed to be less than half of the expression of FAAH activity of wildtype lymphocytes leading to higher peripheral AEA levels in AA/AC allele carriers [7, 8, 10, 11]. In line with these findings, animal studies were able to demonstrate enhanced extinction processes when using cannabinoid agonists or FAAH inhibitors [12-14]. Studies point towards beneficial effects for human carriers of the homozygote $\mathrm{AA}$ and the heterozygote $\mathrm{AC}$ type regarding anxiety processing $[7,15,16]$. Recently, Mayo et al. [8] have found that gene-dependent higher levels of AEA in humans enhanced fear extinction and extinction recall, and that elevated AEA levels in AA homozygous carriers have a protective function during stress-related responses, in a way that AA homozygotes showed no significant decreases in AEA levels after a stress task. However, this effect was not observed for AC heterozygotes [8].

With regard to the neurobiological basis, Hariri et al. [15] found that genetic differences in endocannabinoid signaling in humans modulated threat- and reward-related brain function. A-allele carriers (FAAH C385A SNP) showed lower amygdala activation in a threat-related face processing task and increased activation in the ventral striatum in a reward task [15]. In addition, in their functional magnetic resonance imaging (fMRI) study, Gunduz-Cinar et al. [17] observed that carriers of the A-variant of the allele presented significantly enhanced habituation to threatening faces, a process that was mediated by amygdala activity [17]. In another fMRI study with healthy humans [18], A-allele carriers displayed enhanced frontal cortex-amygdala connectivity during rest, but no differences in emotion regulation strategies during a paradigm with negative pictures [18]. Furthermore, Zabik et al. [19] showed genotype-dependent differential activation in brain regions related to fear conditioning and extinction using an associative learning task, however without effects on the behavioral level [19]. Combined, the A-allele of the SNP rs 324420 has been linked to modulate pain perception [20], lower anxiety [7], and enhanced fear extinction learning [8].

To investigate the mechanisms of fear learning, the most frequently applied paradigm is based on Pavlovian fear conditioning, where an initially neutral stimulus $\left(\mathrm{CS}^{-}\right)$is presented with an unconditioned aversive stimulus (US). After multiple presentations, the neutral stimulus elicits the fear response even in absence of the aversive stimulus, and is, thus, referred to as the conditioned stimulus $\left(\mathrm{CS}^{+}\right)$. For subsequent fear extinction learning, this conditioned stimulus is presented multiple times, which leads to the deletion or reduction of the fear response (extinguished stimulus, $\mathrm{CS}^{\text {+extinguished }}$ ). To test fear extinction learning, the stimuli are presented during extinction recall after fear extinction consolidation [9]. Here, the stimulus is once again presented and the magnitude of the fear response is compared to either another conditioned stimulus (unextinguished stimulus, $\mathrm{CS}^{\text {+unextinguished }}$, which was not displayed during fear extinction learning, or to another neutral stimulus $\left(\mathrm{CS}^{-}\right)$[21]. These paradigms have been highly beneficial to facilitate the understanding of the underlying mechanism during fear learning processes. Regarding the neural networks involved in extinction recall, a recent meta-analysis by Fullana et al. [21] summarized the left anterior and right dorsolateral prefrontal cortex, dorsal aspects of the anterior cingulate, bilateral anterior insular cortex, left parietal operculum and right anterior hippocampus from studies comparing neural activation related to the extinguished stimulus with that related to the unextinguished stimulus.

Based on what is known so far from rodent studies about the role of the FAAH C385A SNP in extinction recall, the present study was designed to investigate its allele-associated effects on the neural signatures of extinction recall in humans. Therefore, 55 healthy male subjects underwent successful Pavlovian-like fear conditioning and fear extinction (see [22]). Extinction recall was then investigated with functional magnetic resonance imaging. We predicted differential neural activation upon an unextinguished relative to an extinguished stimulus, to be greater in AC heterozygotes as compared to $\mathrm{CC}$ homozygotes in regions associated with extinction recall as identified by Fullana et al. ([21]; see above). Behaviorally, carriers of the A-allele of the FAAH C385 SNP as compared to the CC homozygotes were expected to demonstrate lower anxiety ratings as measured by means of task-related subjective ratings of the StateTrait Anxiety Inventory (STAI), and similarly, based on the findings of previous studies [7], we also predicted A-allele carriers to display lower anxiety ratings than $\mathrm{CC}$ individuals on the trait scale.

\section{Materials and methods}

\section{Participants}

55 right-handed, male subjects participated in the study (mean age $=22.8$ years, $\mathrm{SD}=3.0$ years). They were included 
after completing a screening procedure to exclude confounding medical or psychiatric conditions and substance use (see Supplementary Information). Four participants had to be excluded due to acute intake of medication and technical failures. All participants signed an informed consent prior to the study, which was conducted according to the guidelines of the Declaration of Helsinki as approved by the Ethics Board of Ulm University, Germany.

\section{Experimental task during fMRI}

Participants completed a classical Pavlovian fear conditioning, fear extinction, extinction recall paradigm over 3 days (see Fig. 1), which was based on previous experiments [9]. On each day, participants were enrolled between 7 and 9 AM and were instructed to fast overnight, with no breakfast and only water allowed before the experiment to metabolically control AEA levels [3, 23]. During fear conditioning, three different geometric stimuli were presented on a computer screen. One stimulus remained neutral $\left(\mathrm{CS}^{-}\right)$and two stimuli $\left(\mathrm{CS}^{+\mathrm{a}}, \mathrm{CS}^{+\mathrm{b}}\right)$ were coupled with unpleasant thermal stimulation (US) to the right shinbone at a partial reinforcement rate of 50\% (for more details please see Supplementary Information). All stimuli $\left(\mathrm{CS}^{-}, \mathrm{CS}^{+\mathrm{a}}, \mathrm{CS}^{+\mathrm{b}}, \mathrm{CS}^{+\mathrm{a}}+\mathrm{US}, \mathrm{CS}^{+\mathrm{b}}+\mathrm{US}\right)$ were presented 20 times in pseudo-randomized order. To avoid biasing by effects of color or shape, shapes and colors of stimuli were balanced across subjects. In the extinction phase, $\mathrm{CS}^{-}$and $\mathrm{CS}^{+\mathrm{a}}$ were presented 30 times each, without

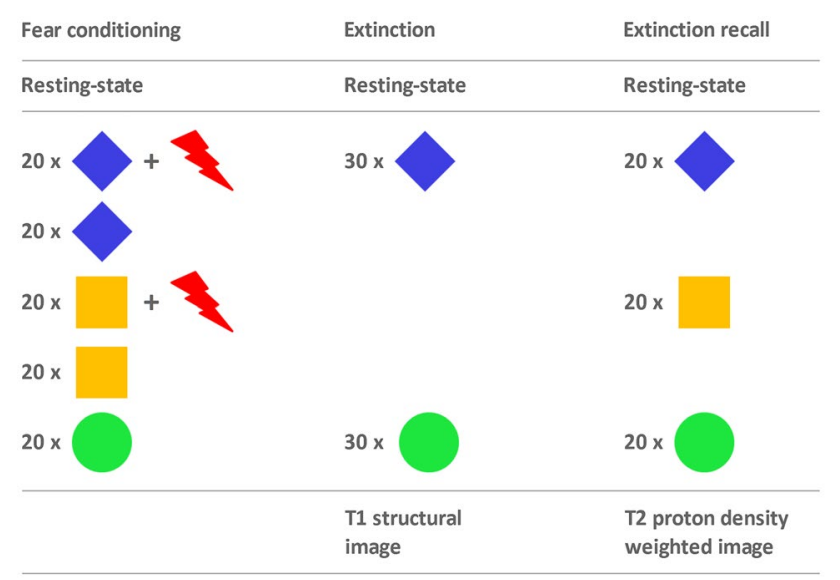

Fig. 1 Schematic overview of the experimental setup over 3 days. Blue and yellow depict the conditioned stimuli $\left(\mathrm{CS}^{+\mathrm{a}}\right.$ and $\left.\mathrm{CS}^{+\mathrm{b}}\right)$, green the neutral stimulus $\left(\mathrm{CS}^{-}\right)$, and the red arrows represent the unconditioned, unpleasant stimulus (US), heat, applied with a thermal stimulation device on the right shinbone. During fear conditioning (day 1), 20 stimuli of each condition were presented $\left(\mathrm{CS}^{-}, \mathrm{CS}^{+\mathrm{a}}\right.$, $\left.\mathrm{CS}^{+\mathrm{b}}, \mathrm{CS}^{+\mathrm{a}}+\mathrm{US}, \mathrm{CS}^{+\mathrm{b}}+\mathrm{US}\right)$ at a reinforcement rate of $50 \%$ in the case of $\mathrm{CS}^{+}+\mathrm{US}$. During fear extinction (day 2), $\mathrm{CS}^{+\mathrm{a}}$ and $\mathrm{CS}^{-}$were presented 30 times each. During extinction recall (day 3), the condi-

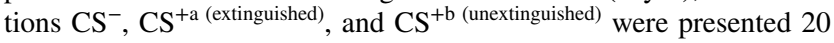
times each presentation of the US. To test extinction recall, all three stimuli $\left(\mathrm{CS}^{-}, \mathrm{CS}^{+\mathrm{a}}, \mathrm{CS}^{+\mathrm{b}}\right)$ were presented 20 times without the US. On all three experimental phases, participants were informed that thermal stimulation was possible. To program and present the trials, Presentation 14.8 (Neurobehavioral Systems Inc., Albany, CA) was used. The stimuli were presented to the participants on a 32" liquid crystal display (LCD) (NordicNeuroLab AS, Bergen, Norway) at a resolution of $1280 \times 720$ pixels, which was installed behind the MR scanner and was visible by means of a double-mirror mounted on top of the head coil. Thermal stimulation was carried out by means of an MRI-compatible ATS thermode $(30 \times 30 \mathrm{~mm}$, TSA-II, Medoc Advanced Medical Systems, Ramat Yishai, Israel).

\section{Blood sampling and FAAH genotyping}

At the very beginning of the entire experimental regimen, $2 \times 7.5 \mathrm{ml}$ EDTA blood samples were obtained from the participants. Deoxyribonucleic acid (DNA) was extracted applying standard protocols of a commercial extraction kit (MagNA Pure 96 DNA and Viral NA Small Volume Kit) and the MagNA Pure 96 (Roche Diagnostics, Mannheim, Germany). Genotyping at $F A A H C 385 \mathrm{~A}$ was performed via realtime quantitative polymerase chain reaction using melting curve detection analysis with Cobas z480 Analyser (LightCycler) (Roche Diagnostics, Mannheim, Germany). The primers were obtained from TIB Molbiol (Berlin, Germany).

\section{Fear and anxiety ratings}

Using a visual analog scale and an MRI-compatible trackball (NAtA TECHNOLOGIES, Coquitlam, Canada), participants were instructed to rate the subjectively perceived fear related to each stimulus before and after the fMRI experiment (How afraid are you of the stimulus coupled to this symbol? [9]. The scale ends were defined as 0 not at all and 10 very much. Ratings were performed while inside the MRI scanner, directly before and after the experiment. Additionally, participants completed the state version of the State-Trait Anxiety Inventory [24] before and after the fMRI session outside the scanner, within 10 min pre- or post-scan, respectively. Unfortunately, STAI scales were only partially completed in some cases so that data from $28 \mathrm{CC}$ and from $12 \mathrm{AC}$ individuals were entered the statistical comparison of pre/ post rating data below. The trait version of the State-Trait Anxiety Inventory was filled out by all but one participant before the start of the entire experimental regimen. Previous studies have suggested that A-allele carriers present lower anxiety scores [7]. Thus, scores were used to investigate if healthy participants differ in their subjective fear and STAI anxiety ratings, with the assumption that A-allele carriers display lower anxiety ratings than $\mathrm{CC}$ individuals. 


\section{MRI data acquisition}

Acquisition of magnetic resonance imaging data was performed on a 3 Tesla MAGNETOM Prisma (Siemens AG, Erlangen, Germany) with a 64-channel head/neck coil. For estimation of task-related brain activation, the T2*weighted blood oxygen level dependent (BOLD) signal was measured using echo-planar imaging with the following parameters: $\mathrm{TR}=2000 \mathrm{~ms}, \mathrm{TE}=33 \mathrm{~ms}$, flip angle $=90^{\circ}$, bandwidth $=2136 \mathrm{~Hz} / \mathrm{Px}$, PAT factor $=2$ (GRAPPA mode), FOV $=220 \mathrm{~mm}$, matrix size $=90 \times 90$, number of slices: 32 , slice orientation: transversal, acquisition: ascending, slice thickness: $3.0 \mathrm{~mm}$, interslice gap $=1.0 \mathrm{~mm}$, voxel size: $2.44 \mathrm{~mm} \times 2.44 \mathrm{~mm} \times 4.00 \mathrm{~mm}$. During the fMRI session 432 EPI volumes were acquired (scan time: $14.3 \mathrm{~min}$ ).

At the participants' second visit, and after completion of the main experimental task, a high-resolution T1-weighted structural image was obtained by administering a 3D magnetisation prepared rapid acquisition gradient echo sequence (MPRAGE; TR $=2300 \mathrm{~ms}, \mathrm{TE}=2.98 \mathrm{~ms}$, inversion time $=900 \mathrm{~ms}$, flip angle $=9^{\circ}, \mathrm{FOV}=256 \mathrm{~mm}$, matrix size: $256 \times 256$, voxel volume $=1 \mathrm{~mm}^{3}$, slice orientation: sagittal; PAT factor $=2($ GRAPPA mode $)$; scan time $=5.21 \mathrm{~min})$.

\section{Whole brain analysis of $\mathrm{FMRI}$ data}

Image pre-processing and analyses were performed using SPM12 according to the standard procedures (see Supplementary Information). A detailed description of the analyses for fear conditioning and fear extinction is reported in Spohrs et al. [22]. Per participant, pre-processed task-based fMRI data were modeled using a single-session-separated general linear model. Extinction recall was modeled with three regressors representing the first three trials of

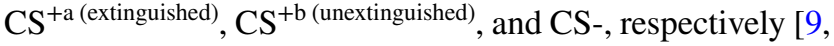
21]. Three further regressors of no interest represented trials 4-20 associated with each condition. Trial onsets were convolved with the canonical hemodynamic response function (HRF) and its temporal derivative. Data were high-pass filtered (frequency cut-off: 1/128 s) to remove low-frequency scanner drifts. An autoregression model of polynomial order 1 was used to account for temporally correlated residual errors. After model estimation, contrast images representing estimated activation for each regressor versus baseline were computed. The contrast images representing the first three trials of $\mathrm{CS}^{+\mathrm{a} \text { (extinguished) }}$ and $\mathrm{CS}^{+\mathrm{b} \text { (unextinguished) }}$ were collected from all participants and subjected to a secondlevel random-effects analysis, implemented in SPM12 as a flexible factorial design with the factors subject, genotype (FAAH) and condition. To investigate neural signaling related to extinction recall irrespective of genotype, an average $t$-contrast across both genotype groups was set up $\left(\mathrm{CS}^{+\mathrm{b} \text { (unextinguished) }}>\mathrm{CS}^{+\mathrm{a} \text { (extinguished) }}\right.$. Next, addressing the prediction of higher neural extinction recall in AC heterozygotes relative to $\mathrm{CC}$ homozygotes, the following $t$-contrast was set up, modeling the direction of the genotype $\times$ condition interaction of interest: $\left(\mathrm{CS}^{+\mathrm{b} \text { (unextinguished) }}{ }_{\mathrm{AC}}>\mathrm{CS}^{+\mathrm{a}}\right.$ (extinguished) $\left.{ }_{\mathrm{AC}}\right)>\left(\mathrm{CS}^{+\mathrm{b} \text { (unextinguished) }}{ }_{\mathrm{CC}}>\mathrm{CS}^{+\mathrm{a} \text { (extinguished) }}{ }_{\mathrm{CC}}\right)$. The thresholds for the resulting statistical parametric maps were set at a voxel-height level of $p<0.001$, uncorrected, and an FWE-corrected cluster threshold of $p<0.05$ corresponding to 173 contiguously significant voxels.

\section{Analysis of fear and anxiety ratings}

Using STATISTICA13 (TIBCO Software Inc., Palo Alto, CA, USA), two separate analyses of variance (ANOVA) for repeated measures were computed to test the hypothesis that A-allele carriers present lower anxiety levels with regard to the subjective fear ratings and the STAI-state anxiety scores.

\section{Results}

\section{FAAH C385A SNP genotyping}

FAAH C385A SNP genotyping revealed 17 AC heterozygous and $34 \mathrm{CC}$ homozygous individuals. Consistent with the rare distribution of AA homozygotes in the population, none of the participants carried this allele combination. As previously reported [22], mean plasma levels of AEA obtained from blood samples taken before the entire experimental regimen were significantly $(t(49)=2.81, p=0.007)$ higher in $\mathrm{AC}$ heterozygotes $\left([\mathrm{AEA}]_{\mathrm{AC}}=0.49 \pm 0.16 \mathrm{pmol} /\right.$ $\mathrm{ml}$ ) compared to the individuals homozygous for the $\mathrm{C}$-allele $\left([\mathrm{AEA}]_{\mathrm{CC}}=0.38 \pm 0.13 \mathrm{pmol} / \mathrm{ml}\right)($ Cohen's $d=0.755)$.

\section{Neuroimaging data}

\section{FAAH C385A SNP whole-brain group differences and neural extinction recall signaling}

At the given significance level, for the entire sample, no clusters were found for the main effect of extinction recall. At an uncorrected level $(p<0.001)$, this contrast revealed one cluster in the left anterior insula that did not, however, survive correction for multiple comparisons (cluster size: 38 voxels; peak coordinates: $-36,28,4$; $z$-score: 4.73 ).

Between-groups contrasting showed that AC heterozygotes relative to $\mathrm{CC}$ homozygotes had significantly greater differential neural activation related to extinction recall in the following brain regions (Fig. 2 and Table 1): bilateral anterior and middle cingulate cortex, bilateral anterior and middle insular cortex, bilateral superior temporal gyrus, right Rolandic operculum, left middle temporal gyrus, left postcentral gyrus, and right caudate nucleus (whole-brain 

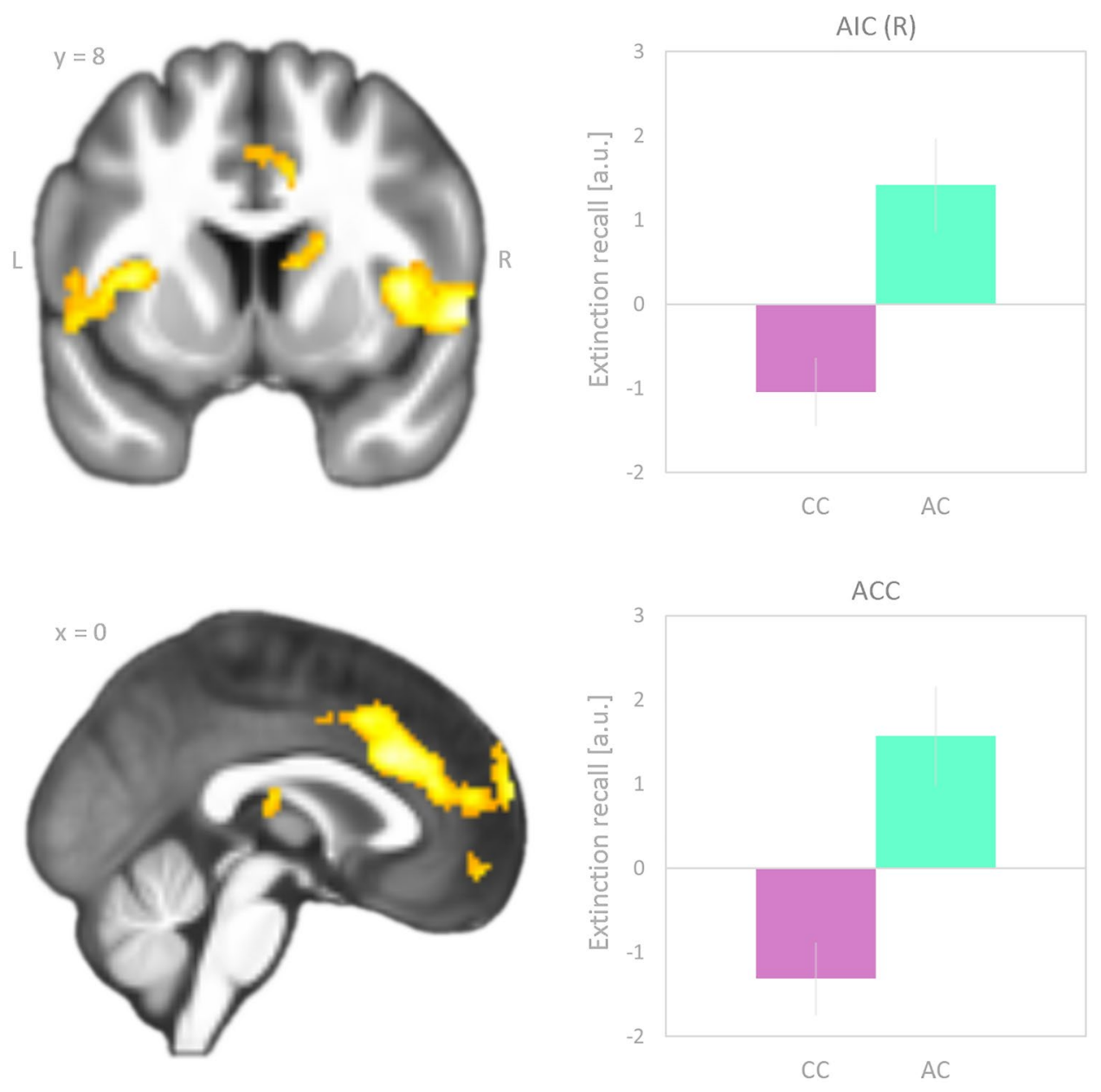

Fig. 2 Brain regions where carriers of the FAAH A-allele, relative to $\mathrm{CC}$ homozygotes, displayed a significantly greater effect of extinction recall, defined as the difference " $\mathrm{CS}^{+\mathrm{b} \text { (unextinguished) }}$ minus $\mathrm{CS}^{+\mathrm{a} \text { (extin- }}$ guished)', As previously introduced [21, 41, 42], a positive going contrast value indicates extinction recall, while a negative going contrast value indicates the reverse. This is exemplified by the bar graphs on the right side of the figure, for two representative brain regions, the right anterior insula (AIC) and the anterior cingulate cortex (ACC).

analysis, voxel level $p<0.001$, cluster level $p<0.05$, FWE corrected, corresponding to 173 voxels).

\section{Subjective fear ratings}

Subjective fear ratings confirmed the validity of the conditioning-extinction-extinction recall paradigm. For data regarding fear conditioning, please refer to Spohrs et al. [22]. As a marker for successful extinction recall, the difference between ratings for the $\mathrm{CS}^{+\mathrm{a} \text { (extinguished) }}$ pre $(M=5.08, \mathrm{SD}=2.88)$ and the $\mathrm{CS}^{+\mathrm{b} \text { (unextinguished) }}$ pre $(M=5.78, \mathrm{SD}=3.12)$ was significant $(t(50)=1.98$, $p=0.027$, one-tailed). The difference between the $\mathrm{CS}^{+\mathrm{a}}$ (extinguished) pre and the neutral stimulus $\mathrm{CS}^{-}$pre $(M=0.98$, $\mathrm{SD}=1.61)$ was also significant $(t(50)=9.97, p<0.001)$.

Significance was assessed at $p<0.001$ (voxel level) and $p<0.05$ (cluster level FWE corrected, corresponding to 173 voxels). The statistical parametric map was superimposed on coronal and sagittal sections of the group averaged T1 image. Coordinates refer to Montreal Neurological Institute (MNI) space. Differential parameter estimates were extracted from the right anterior insula (869 voxels; upper right panel) and the anterior cingulate cortex (2341 voxels; lower right panel). a.u. arbitrary unit; $L$ left; $R$ right

When looking at the post experimental differences between the extinguished stimulus $\left(\mathrm{CS}^{+\mathrm{a} \text { (extinguished) }}\right.$ post: $M=2.72, \mathrm{SD}=2.68)$ and the neutral stimulus $\left(\mathrm{CS}^{-}\right.$post: $M=0.52, \mathrm{SD}=1.34)$, these differences remain significant after extinction recall $(\mathrm{t}(50)=5.38, p<0.001)$. The same holds for the unextinguished stimulus $\left(\mathrm{CS}^{+\mathrm{b}}\right.$ (unextinguished) post: $M=2.98, \mathrm{SD}=2.60)$ and the neutral stimulus $(t$ $(50)=6.03, p<0.001)$. To check for differences between the $F A A H$ genotype (AC vs. CC individuals), a repeatedmeasures ANOVA with the factors time point (pre, post), genotype and stimulus, was performed, which revealed no significant main effect for genotype $(F(1,49)=0.18$, $p=0.669)$, while main factors time point $(F(1,49)=67.75$, $p<0.001)$ and stimulus $(F(2,98)=53.98, p<0.001)$ were significant as expected. However, there was no significant 
Table 1 Brain regions showing a higher signal $\left(\mathrm{CS}^{+\mathrm{b} \text { (unextinguished) }}>\mathrm{CS}^{+}\right.$ a (extinguished) related to extinction recall in the FAAH AC heterozygotes as compared to the CC homozygotes

\begin{tabular}{|c|c|c|c|c|c|c|}
\hline & \multirow[t]{2}{*}{ Brain region } & \multirow{2}{*}{$\begin{array}{l}\text { Number of } \\
\text { voxels }\end{array}$} & \multicolumn{4}{|c|}{ Peak voxel (MNI space) } \\
\hline & & & $x$ & $y$ & $z$ & $z$-score \\
\hline \multirow[t]{2}{*}{$\mathrm{L}$} & Medial superior frontal gyrus & 2341 & -6 & 62 & 22 & 4.58 \\
\hline & Dorsal anterior cingulate & & 0 & 24 & 30 & 4.45 \\
\hline $\mathrm{R}$ & Dorsal anterior cingulate & & 4 & 40 & 22 & 4.32 \\
\hline $\mathrm{L}$ & Anterior insula & 303 & -34 & 6 & 8 & 4.29 \\
\hline $\mathrm{L}$ & Middle insula & & -42 & 2 & -2 & 3.58 \\
\hline $\mathrm{R}$ & Anterior insula & 869 & 40 & 12 & 6 & 4.69 \\
\hline $\mathrm{R}$ & Middle insula & & 48 & 2 & 0 & 4.15 \\
\hline $\mathrm{R}$ & Superior temporal pole & & 58 & 6 & 0 & 4.67 \\
\hline $\mathrm{L}$ & Superior temporal gyrus & 278 & -62 & -14 & 4 & 4.27 \\
\hline $\mathrm{L}$ & Middle temporal gyrus & & -52 & -30 & 4 & 4.13 \\
\hline $\mathrm{L}$ & Postcentral gyrus & 287 & -60 & -18 & 32 & 4.56 \\
\hline $\mathrm{L}$ & Postcentral gyrus & & -48 & -22 & 46 & 3.86 \\
\hline $\mathrm{R}$ & Caudate nucleus & 506 & 12 & 4 & 14 & 4.36 \\
\hline $\mathrm{R}$ & Caudate nucleus & & 20 & 22 & 2 & 3.88 \\
\hline
\end{tabular}

$n=51$

Significance: $p<0.001$ (voxel level) and FWE-corrected $(p<0.05)$ cluster sizes corresponding to 173 contiguous voxels, whole-brain analysis

$L$ left; $R$ right. $M N I$ Montreal Neurological Institute interaction of all three main factors time point by stimulus by genotype $(F(2,98)=2.07, p=0.131)$.

\section{STAI-S and STAI-T}

Comparison of state anxiety ratings (STAI-S) between CC and $\mathrm{AC}$ individuals before the extinction recall did not show a statistically significant group difference $(t(38)=1.94$, $p=0.059)$, while average rating scores of the CC group (mean $=35.2 \pm 5.1)$ were numerically higher than those of the AC group (mean $=31.8 \pm 5.2$ ) (Cohen's $d=0.686$ ). After the extinction recall fMRI session, STAI-S ratings differed significantly $(t(38)=2.92, p=0.006)$ between CC $($ mean $=33.6 \pm 4.6)$ and $\mathrm{AC}($ mean $=29.2 \pm 3.8)$ individuals (Cohen's $d=1.01$ ) (Fig. 3). Assuming that the numerical group difference before the extinction recall fMRI experiment might have conditioned the group difference afterwards, the test for group differences was repeated using a repeated-measures ANCOVA where individual state anxiety ratings before the experiment entered the analysis as covariate to compensate for these numerical differences at this time point (baseline correction). This computation revealed indeed a significant time point by covariate interaction $(F(1,37)=15.65, p<0.001)$, while the interaction of both main factors time point and genotype remained significant $(F(1,37)=4.23, p=0.047)$, indicating that the pre-to-post decrease in state anxiety ratings of the AC group (2.6 score units) was significantly greater than that of the $\mathrm{CC}$ group (1.6 score units) despite the numerical group difference before the experiment.

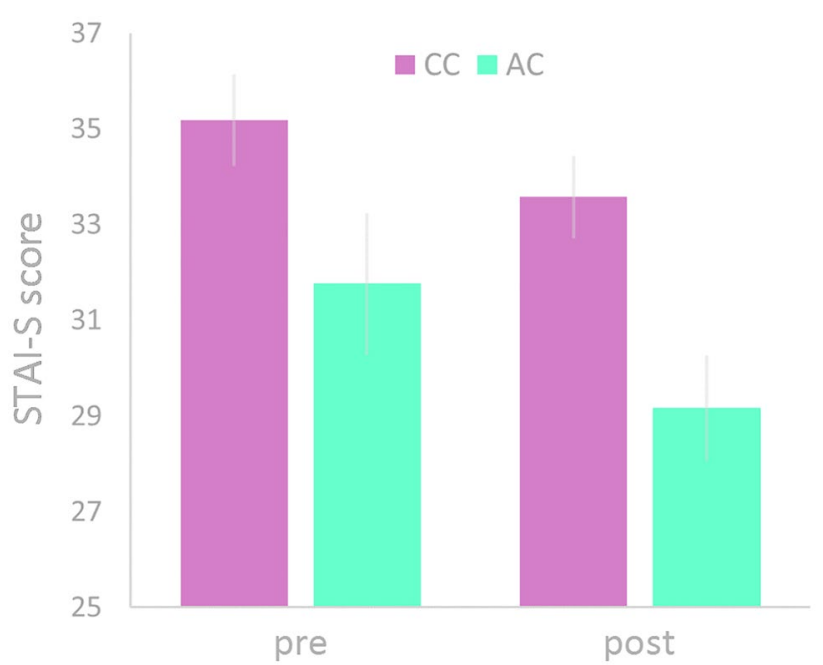

Fig. 3 Genotype-related group differences in the state version of the State-Trait Anxiety Inventory (STAI-S) before (pre) and after (post) the extinction recall fMRI experiment. Bars represent group averages; error bars denote the standard error of the mean

For the trait version of the STAI, a two-sample $t$-test did not reveal a significant difference between $F A A H$ AC and CC individuals $(t(49)=0.44, p=0.659)$. The observed mean values of $33.4( \pm 6.4, \mathrm{CC}$ group) and $32.3( \pm 6.5$, $\mathrm{AC}$ group) are average compared to normative values for the German version of the STAI-T for 15- to 29-year-old men with $T$-values of 50 and 49 and percentile ranks of 49 and 45 , respectively. 


\section{Discussion}

Aim of this study was to address whether the SNP rs 324420 of the FAAH gene, which codes for the endocannabinoid anandamide (AEA) degrading enzyme, modulates neural and behavioral correlates of extinction recall, after successful fear conditioning and fear extinction. Carriers of the A-allele of this SNP are reported to have higher levels of circulating AEA relative to subjects homozygous for the $\mathrm{C}$-allele. Between-group comparisons revealed that $\mathrm{AC}$ heterozygotes showed greater neural activation differences relative to CC homozygotes in core neural structures related to extinction recall, which have previously been reported in a meta-analysis [21]. While there was no clear genotype effect on fear ratings of the extinguished and unextinguished stimuli, groups differed in their state anxiety ratings, particularly after the extinction recall experiment. Trait-related anxiety group differences were not evident.

\section{FAAH C385A SNP group differences and neural extinction recall signaling}

While we previously found no effect of genotype on neural correlates of fear extinction learning [22], contrasting the differential effect of extinction recall in the group of AC heterozygotes (FAAH C385A SNP) with that in the group of CC homozygotes, showed significantly greater differential neural activation in several brain regions, in accordance with prior reports [21]. Results presented here support involvement of core regions of the salience network, particularly the AIC and the ACC. From that, the group difference during extinction recall can be interpreted in a way that in the AC group greater salience network reactivity was observed upon $\mathrm{CS}^{+ \text {unextinguished }}$ than upon $\mathrm{CS}^{+ \text {extinguished }}$, which might represent a more successful recall of salience extinction as compared to the $\mathrm{CC}$ group with the reverse situation. The salience network is assumed to play a central role in emotional control and emotional processing, given its activation during the integration of sensory, cognitive and emotional input, mediation of interoceptive awareness and interaction with other networks subserving memory-related processing [28, 29]. Furthermore, a dysfunction in networks including ACC and AIC has been discussed as a potential transdiagnostic marker in psychiatric disorders [25-27]. Using a region of interest approach, Zabik et al. [19] found less amygdala activation related to the previously extinguished cue in A-allele carriers, which could be interpreted in line with our findings. However, as Zabik et al. [19] investigated trauma-exposed individuals and memory consolidation was only allowed for only 10 min after conditioning in 45 of 59 subjects, comparability of the studies remains unclear. Furthermore, while fear ratings in our study confirmed the validity of our conditioning-extinction-extinction recall paradigm [22], neither skin conductance measures nor subjective fear ratings were presented to demonstrate that the unconditioned stimulus (3D virtual snake striking toward participant's viewpoint) used was indeed suited to induce fear [19].

Following previous studies, the ACC seems to play a major role during fear extinction recall in PTSD patients, who frequently show disturbances in extinction recall and exhibit altered activation of the ACC, the hippocampus, amygdala, and ventromedial prefrontal cortex, as compared to trauma-exposed healthy controls [30-32]. In addition, AIC hyperactivity has been implied in anxiety disorders, such as generalized anxiety disorder, social phobia, and again PTSD [33, 34].

Previous human and rodent studies were able to demonstrate enhanced extinction processes in FAAH C385A carriers [7] given that degradation of AEA is reduced in these subjects leading to increased levels of circulating AEA. For example, mice A-allele carriers with higher levels of AEA presented decreased freezing behavior and both, human and mice A-allele carriers, displayed greater fronto-amygdala connectivity during resting-state fMRI interpreted as a biological trait marker to cope with emotionally relevant stress. Moreover, present findings are congruent with results from Mayo et al. [35], who, in one of the first FAAH inhibitor studies, found no differences in fear extinction learning between an experimental group and control group, but significant behavioral effects during extinction recall. Results were interpreted to indicate improvement of the consolidation of the learned fear extinction when AEA levels are higher [35].

Considering the effect of the FAAH rs 324420 SNP on subjective experiences of anxiety, the present data are to be interpreted with care. While the anxiety ratings generally corroborated the validity of the experimental setup, the differences in fear ratings after the extinction recall session remained significant when comparing the extinguished and the unextinguished stimulus against the neutral stimulus. Cognitive factors might have played a role, as well as the duration of the extinction recall session, which are factors that should be addressed in a replication.

For the STAI-S, there was a significant effect of genotype indicated by the group by time interaction when taking into account numerical differences before entering the extinction recall experiment, which presumably stem from genotyperelated different success of previous extinction learning. The observation of a genotype effect on state anxiety ratings from the STAI is in good accordance with previous work [7] and complements previous suggestions [7, 35], that 
gene-dependent elevation of AEA levels may promote fear extinction learning and recall and that neural functioning in the fronto-temporal-limbic circuit underlying extinction recall may be directly modulated by endocannabinoid signaling. These findings match with previous research conducted in rodents, where CB1 receptor agonism or inhibition of FAAH have enhanced fear extinction learning [36] and its consolidation as tested during fear extinction recall $[7,17$, 37]. However, it is noteworthy to stress the importance of the time point of application as well as the individual and taskrelated fluctuations in the endocannabinoids, which should be subjected to future translational research [38].

\section{Limitations}

The results are well suited to enhance the understanding of the underlying mechanisms associated with fear extinction learning. However, the study sample consisted of healthy, young, male students only, so that we were unable to determine any effects of sex and/or gender. Secondly, a transfer of the results to a clinical patient setting is limited and remains subject to future research. Next, although the sample size is rather large for an fMRI study, regarding genetic effects, a larger sample is usually required, and the results need to be interpreted with caution. Furthermore and based on previous studies, that used similar sample sizes [7], we focused solely on the FAAH SNP rs324420, and thus lack the possibility to control for population stratification effects that might be present in our Caucasian sample. Since these effects cannot be ruled out, a replication in a larger sample assessing more and unlinked genetic markers is important.

\section{Future directions}

Recent reviews and studies highlight the beneficial modulatory effects of the endocannabinoid system regarding symptom alleviation and treatment of stress and anxiety disorders. Furthermore, studies have pointed out altered endocannabinoid levels in people suffering from these disorders, pointing towards a role of the endocannabinoid system not only in the treatment, but also in the development of these disorders. As recent studies have emphasized, targeting the ECS via, e.g., FAAH inhibition to enhance fear extinction learning and extinction recall seems to be a promising approach for the advancement of current psychopharmacological and psychotherapeutic treatments $[35,39,40]$. The data presented here support the potentially modulatory role of the ECS. However, more research in humans is necessary to gain a still better understanding of the underlying processes, especially before and after psychotherapeutic approaches such as exposure therapy.
Supplementary Information The online version contains supplementary material available at https://doi.org/10.1007/s00406-021-01367-4.

Acknowledgements The authors are highly grateful to Kathrin Brändle, Heidrun Haas and Claudia Schwitter for their work and support in the laboratory.

Author contributions All authors contributed to the study conception and design. Material preparation, data collection and analysis were performed by JS, MU and BA. The first draft of the manuscript was written by JS and all authors commented on previous versions of the manuscript. All authors read and approved the final manuscript.

Funding Open Access funding enabled and organized by Projekt DEAL. No funding was received for conducting this study.

Availability of data and material Data and material can be shared upon individual request to the authors.

Code availability Not applicable.

\section{Declarations}

Conflict of interest PLP has received funding from the German Federal Ministry of Education and Research (BMBF), the German Federal Institute for Drugs and Medical Devices (BfARM), the Volkswagen Foundation, the Baden-Wuerttemberg Foundation, Servier and Lundbeck. He received a speaker's honorarium from Shire. The other authors declare no conflicts of interest.

Ethics approval The study was conducted according to the guidelines of the Declaration of Helsinki and approved by the Ethics Board of Ulm University, Germany.

Consent to participate All participants signed an informed consent prior to their inclusion in the study.

Consent for publication All participants signed an informed regarding publishing their data.

Open Access This article is licensed under a Creative Commons Attribution 4.0 International License, which permits use, sharing, adaptation, distribution and reproduction in any medium or format, as long as you give appropriate credit to the original author(s) and the source, provide a link to the Creative Commons licence, and indicate if changes were made. The images or other third party material in this article are included in the article's Creative Commons licence, unless indicated otherwise in a credit line to the material. If material is not included in the article's Creative Commons licence and your intended use is not permitted by statutory regulation or exceeds the permitted use, you will need to obtain permission directly from the copyright holder. To view a copy of this licence, visit http://creativecommons.org/licenses/by/4.0/.

\section{References}

1. Breslau J, Kendler KS, Su M, Gaxiola-Aguilar S, Kessler RC (2005) Lifetime risk and persistence of psychiatric disorders across ethnic groups in the United States. Psychol Med 35:317327. https://doi.org/10.1017/s0033291704003514 
2. Cuijpers P, Cristea IA, Karyotaki E, Reijnders M, Huibers MJH (2016) How effective are cognitive behavior therapies for major depression and anxiety disorders? A meta-analytic update of the evidence. World Psychiatry 15:245-258. https://doi.org/10.1002/ wps. 20346

3. Hillard CJ (2018) Circulating endocannabinoids: from whence do they come and where are they going? Neuropsychopharmacology 43:155-172

4. Lutz B, Marsicano G, Maldonado R, Hillard CJ (2015) The endocannabinoid system in guarding against fear, anxiety and stress. Nat Rev Neurosci 16:705-718. https://doi.org/10.1038/nrn4036

5. Neumeister A, Normandin MD, Pietrzak RH, Piomelli D, Zheng MQ, Gujarro-Anton A, Potenza MN, Bailey CR, Lin SF, Najafzadeh S, Ropchan J, Henry S, Corsi-Travali S, Carson RE, Huang Y (2013) Elevated brain cannabinoid CB1 receptor availability in post-traumatic stress disorder: a positron emission tomography study. Mol Psychiatry 18:1034-1040. https://doi.org/10.1038/mp. 2013.61

6. Di Marzo V, Bifulco M, De Petrocellis L (2004) The endocannabinoid system and its therapeutic exploitation. Nat Rev Drug Discov 3:771-784. https://doi.org/10.1038/nrd1495

7. Dincheva I, Drysdale AT, Hartley CA, Johnson DC, Jing D, King EC, Ra S, Gray JM, Yang R, DeGruccio AM, Huang C, Cravatt BF, Glatt CE, Hill MN, Casey BJ, Lee FS (2015) FAAH genetic variation enhances fronto-amygdala function in mouse and human. Nat Commun 6:6395. https://doi.org/10.1038/ncomm s7395ncomms7395

8. Mayo LM, Asratian A, Linde J, Holm L, Natt D, Augier G, Stensson N, Vecchiarelli HA, Balsevich G, Aukema RJ, Ghafouri B, Spagnolo PA, Lee FS, Hill MN, Heilig M (2018) Protective effects of elevated anandamide on stress and fear-related behaviors: translational evidence from humans and mice. Mol Psychiatry. https:// doi.org/10.1038/s41380-018-0215-1

9. Lonsdorf TB, Menz MM, Andreatta M, Fullana MA, Golkar A, Haaker J, Heitland I, Hermann A, Kuhn M, Kruse O, Meir Drexler S, Meulders A, Nees F, Pittig A, Richter J, Romer S, Shiban Y, Schmitz A, Straube B, Vervliet B, Wendt J, Baas JMP, Merz CJ (2017) Don't fear "fear conditioning": Methodological considerations for the design and analysis of studies on human fear acquisition, extinction, and return of fear. Neurosci Biobehav Rev 77:247-285. https://doi.org/10.1016/j.neubiorev.2017.02.026

10. Chiang KP, Gerber AL, Sipe JC, Cravatt BF (2004) Reduced cellular expression and activity of the P129T mutant of human fatty acid amide hydrolase: evidence for a link between defects in the endocannabinoid system and problem drug use. Hum Mol Genet 13:2113-2119. https://doi.org/10.1093/hmg/ddh216

11. Boileau I, Westwood D, Richardson D, Rhind S, Tyndale RF, Lanius R, Bazinet R, Lobaugh NJ, Houle S (2018) Investigating Endocannabinoid Mechanisms in Posttraumtic Stress Disorder: Neuroimaging Studies with the Novel Fatty Acid Amide Hydrolase Probe (11C)CURB. Biol Psych 83:S21. https://doi.org/10. 1016/j.biopsych.2018.02.068

12. Gunduz-Cinar O, Hill MN, McEwen BS, Holmes A (2013) Amygdala FAAH and anandamide: mediating protection and recovery from stress. Trends Pharmacol Sci 34:637-644. https://doi.org/ 10.1016/j.tips.2013.08.008

13. Lin HC, Mao SC, Su CL, Gean PW (2009) The role of prefrontal cortex CB1 receptors in the modulation of fear memory. Cereb Cortex 19:165-175. https://doi.org/10.1093/cercor/bhn075

14. Pamplona FA, Prediger RD, Pandolfo P, Takahashi RN (2006) The cannabinoid receptor agonist WIN 55,212-2 facilitates the extinction of contextual fear memory and spatial memory in rats. Psychopharmacology 188:641-649. https://doi.org/10.1007/ s00213-006-0514-0
15. Hariri AR, Gorka A, Hyde LW, Kimak M, Halder I, Ducci F, Ferrell RE, Goldman D, Manuck SB (2009) Divergent effects of genetic variation in endocannabinoid signaling on human threatand reward-related brain function. Biol Psychiatry 66:9-16. https://doi.org/10.1016/j.biopsych.2008.10.047

16. Spagnolo PA, Ramchandani VA, Schwandt ML, Kwako LE, George DT, Mayo LM, Hillard CJ, Heilig M (2016) FAAH gene variation moderates stress response and symptom severity in patients with posttraumatic stress disorder and comorbid alcohol dependence. Alcohol Clin Exp Res 40:2426-2434. https://doi.org/ 10.1111/acer. 13210

17. Gunduz-Cinar O, MacPherson KP, Cinar R, Gamble-George J, Sugden K, Williams B, Godlewski G, Ramikie TS, Gorka AX, Alapafuja SO, Nikas SP, Makriyannis A, Poulton R, Patel S, Hariri AR, Caspi A, Moffitt TE, Kunos G, Holmes A (2013) Convergent translational evidence of a role for anandamide in amygdala-mediated fear extinction, threat processing and stressreactivity. Mol Psychiatry 18:813-823. https://doi.org/10.1038/ mp. 2012.72

18. Gärtner A, Dorfel D, Diers K, Witt SH, Strobel A, Brocke B (2019) Impact of FAAH genetic variation on fronto-amygdala function during emotional processing. Eur Arch Psychiatry Clin Neurosci 269:209-221. https://doi.org/10.1007/ s00406-018-0944-9

19. Zabik NL, Iadipaolo AS, Marusak HA, Peters C, Burghardt K, Rabinak CA (2021) A common genetic variant in fatty acid amide hydrolase is linked to alterations in fear extinction neural circuitry in a racially diverse, nonclinical sample of adults. J Neurosc Res 00:1-18. https://doi.org/10.1002/jnr.24860

20. Cajanus K, Holmstrom EJ, Wessman M, Anttila V, Kaunisto MA, Kalso E (2016) Effect of endocannabinoid degradation on pain: role of FAAH polymorphisms in experimental and postoperative pain in women treated for breast cancer. Pain 157:361-369. https://doi.org/10.1097/j.pain.0000000000000398

21. Fullana MA, Albajes-Eizagirre A, Soriano-Mas C, Vervliet B, Cardoner N, Benet O, Radua J, Harrison BJ (2018) Fear extinction in the human brain: a meta-analysis of fMRI studies in healthy participants. Neurosci Biobehav Rev 88:16-25. https://doi.org/10. 1016/j.neubiorev.2018.03.002

22. Spohrs J, Ulrich M, Gron G, Prost M, Plener PL, Fegert JM, Bindila L, Abler B (2021) Fear extinction learning and anandamide: an fMRI study in healthy humans. Transl Psychiatry. https:// doi.org/10.1038/s41398-020-01177-7

23. Gatta-Cherifi B, Matias I, Vallee M, Tabarin A, Marsicano G, Piazza PV, Cota D (2012) Simultaneous postprandial deregulation of the orexigenic endocannabinoid anandamide and the anorexigenic peptide YY in obesity. Int J Obes 36:880-885. https://doi. org/10.1038/ijo.2011.165

24. Spielberger CD, Gorsuch RL, Lushene RE (1971) State-trait anxiety inventory, manual for the state-trait anxiety inventory. Consulting Psychologist Press, Palo Alto

25. Goodkind M, Eickhoff SB, Oathes DJ, Jiang Y, Chang A, JonesHagata LB, Ortega BN, Zaiko YV, Roach EL, Korgaonkar MS, Grieve SM, Galatzer-Levy I, Fox PT, Etkin A (2015) Identification of a common neurobiological substrate for mental illness. JAMA Psychiat 72:305-315. https://doi.org/10.1001/jamapsychi atry.2014.22062108651[pii]

26. Janiri D, Moser DA, Doucet GE, Luber MJ, Rasgon A, Lee WH, Murrough JW, Sani G, Eickhoff SB, Frangou S (2020) Shared neural phenotypes for mood and anxiety disorders: a meta-analysis of 226 task-related functional imaging studies. JAMA Psychiat 77:172-179. https://doi.org/10.1001/jamapsychiatry.2019.33512 753513

27. Sha Z, Wager TD, Mechelli A, He Y (2019) Common dysfunction of large-scale neurocognitive networks across psychiatric 
disorders. Biol Psychiatry 85:379-388. https://doi.org/10.1016/j. biopsych.2018.11.011

28. Craig AD (2009) How do you feel-now? The anterior insula and human awareness. Nat Rev Neurosci 10:59-70. https://doi.org/10. $1038 /$ nrn2555

29. Menon V (2015) The salience network. Brain mapping: an encyclopedic reference. Elsevier, Stanford, CA, USA, pp 597-611

30. Helpman L, Marin MF, Papini S, Zhu X, Sullivan GM, Schneier F, Neria M, Shvil E, Malaga Aragon MJ, Markowitz JC, Lindquist MA, Wager T, Milad M, Neria Y (2016) Neural changes in extinction recall following prolonged exposure treatment for PTSD: a longitudinal fMRI study. NeuroImage Clinical 12:715-723. https://doi.org/10.1016/j.nicl.2016.10.007

31. Milad MR, Quirk GJ (2012) Fear extinction as a model for translational neuroscience: ten years of progress. Annu Rev Psychol 63(63):129-151. https://doi.org/10.1146/annurev.psych.121208. 131631

32. Suarez-Jimenez B, Albajes-Eizagirre A, Lazarov A, Zhu X, Harrison BJ, Radua J, Neria Y, Fullana MA (2019) Neural signatures of conditioning, extinction learning, and extinction recall in posttraumatic stress disorder: a meta-analysis of functional magnetic resonance imaging studies. Psychol Med. https://doi.org/10.1017/ S0033291719001387

33. Paulus MP, Stein MB (2006) An insular view of anxiety. Biol Psychiatry 60:383-387. https://doi.org/10.1016/j.biopsych.2006. 03.042

34. Peterson A, Thome J, Frewen P, Lanius RA (2014) Resting-state neuroimaging studies: a new way of identifying differences and similarities among the anxiety disorders? Canadian journal of psychiatry. Revue canadienne de psychiatrie 59:294-300. https://doi. org/10.1177/070674371405900602

35. Mayo LM, Asratian A, Linde J, Holm L, Natt D, Augier G, Stensson N, Vecchiarelli HA, Balsevich G, Aukema RJ, Ghafouri B, Spagnolo PA, Lee FS, Hill MN, Heilig M (2020) Protective effects of elevated anandamide on stress and fear-related behaviors: translational evidence from humans and mice. Mol Psychiatry 25:993-1005. https://doi.org/10.1038/s41380-018-0215-1

36. Morena M, Berardi A, Colucci P, Palmery M, Trezza V, Hill MN, Campolongo P (2018) Enhancing endocannabinoid neurotransmission augments the efficacy of extinction training and ameliorates traumatic stress-induced behavioral alterations in rats. Neuropsychopharmacology 43:1284-1296. https://doi.org/10. 1038/npp.2017.305

37. Bitencourt RM, Pamplona FA, Takahashi RN (2008) Facilitation of contextual fear memory extinction and anti-anxiogenic effects of AM404 and cannabidiol in conditioned rats. Eur Neuropsychopharmacol 18:849-859. https://doi.org/10.1016/j.euroneuro. 2008.07.001

38. Lisboa SF, Vila-Verde C, Rosa J, Uliana DL, Stern CAJ, Bertoglio LJ, Resstel LB, Guimaraes FS (2019) Tempering aversive/traumatic memories with cannabinoids: a review of evidence from animal and human studies. Psychopharmacology 236:201-226. https://doi.org/10.1007/s00213-018-5127-x

39. Rabinak CA, Phan KL (2014) Cannabinoid modulation of fear extinction brain circuits: a novel target to advance anxiety treatment. Curr Pharm Des 20:2212-2217. https://doi.org/10.2174/ 13816128113199990437

40. Papagianni EP, Stevenson CW (2019) Cannabinoid regulation of fear and anxiety: an update. Curr Psychiatry Rep 21:38. https:// doi.org/10.1007/s11920-019-1026-z

41. Milad MR, Quirk GJ, Pitman RK, Orr SP, Fischl B, Rauch SL (2007) A role for the human dorsal anterior cingulate cortex in fear expression. Biol Psychiatry 62:1191-1194. https://doi.org/ 10.1016/j.biopsych.2007.04.032

42. Rabinak CA, Angstadt M, Lyons M, Mori S, Milad MR, Liberzon I, Phan KL (2014) Cannabinoid modulation of prefrontal-limbic activation during fear extinction learning and recall in humans. Neurobiol Learn Mem 113:125-134. https://doi.org/10.1016/j. nlm.2013.09.009 